\title{
On The Mean First Exit Time For A Compound Poisson Process
}

\author{
Gamze Ozel ${ }^{1}$ \\ ${ }^{1}$ Department of Statistics, Hacettepe University
}

\begin{abstract}
In this study, first exit time of a compound Poisson process with positive jumps and an upper horizontal boundary is considered. An explicit formula is derived for the mean first exit time associated with the compound Poisson process. Finally, an application on traffic accidents is given to illustrate the usage of the mean first exit time.
\end{abstract}

Key words: Compound Poisson process, First exit time, Upper horizontal boundary, Mean

\section{Introduction}

Let $\left\{\mathrm{N}_{\mathrm{t}}, \mathrm{t} \geq 0\right\}$ be a homogeneous Poisson process and let $\mathrm{Y}_{\mathrm{i}}, \mathrm{i}=1,2,3, \ldots$, be i.i.d. random variables, independent of the process $\left\{\mathrm{N}_{\mathrm{t}}, \mathrm{t} \geq 0\right\}$. A stochastic process $\left\{\mathrm{X}_{\mathrm{t}}, \mathrm{t} \geq 0\right\}$ is said to be a compound Poisson process if it is represented as

$$
X_{t}=\sum_{i=1}^{N_{t}} Y_{i}
$$

If $\mathrm{E}\left(\mathrm{Y}_{\mathrm{i}}\right)=\eta, \mathrm{V}\left(\mathrm{Y}_{\mathrm{i}}\right)=\sigma^{2}, \mathrm{i}=1,2,3, \ldots$, the expected value and variance of $\mathrm{X}_{\mathrm{t}}$ are $\mathrm{E}\left(\mathrm{X}_{\mathrm{t}}\right)=\lambda \mathrm{t} \eta$, $\mathrm{V}(\mathrm{X})=\lambda \mathrm{t}\left(\sigma^{2}+\eta^{2}\right)$, respectively. In particular, if $Y_{i}, i=1,2,3, \ldots$, are Poisson distributed in (1), $\left\{\mathrm{X}_{\mathrm{t}}, \mathrm{t} \geq 0\right\}$ is called as a Neyman type A process and if $\mathrm{Y}_{\mathrm{i}}, \mathrm{i}=1,2,3, \ldots$, are distributed according to the binomial distribution, $\left\{\mathrm{X}_{\mathrm{t}}, \mathrm{t} \geq 0\right\}$ is called as a Neyman type B process. Similarly, if $\mathrm{Y}_{\mathrm{i}}$, $\mathrm{i}=1,2,3, \ldots$, are geometric distributed, $\left\{\mathrm{X}_{\mathrm{t}}, \mathrm{t} \geq 0\right\}$ is called as a Polya-Aeppli process [1].

The statistical significance of the compound Poisson process arises from its applicability in real life situations, where the researcher often observes only the total amount $X_{t}$, which is composed of an unknown random number $N_{t}$ of random contributions $Y_{i}, i=1,2,3, \ldots$ The probability function for $X_{t}$ is obtained by Ozel and Inal [2] where $Y_{i}, i=1,2,3, \ldots$ are discrete random variables.

Concerning applications, the first exit time can be defined as the length of the busy period for a $\mathrm{M} / \mathrm{G} / 1$ queue in queuing theory [3]. In risk analysis, the distribution function of the first exit time is 
that of the first time at which the accumulated total claims from an insurance company exceeds its capital. Besides these, the first exit time is defined as the first time until either outdating or total depletion of stock for perishable items in inventory theory [4].

Laplace transforms of the distribution function of the first exit time with two parallel boundaries were derived by Dvoretzky et al. [5] for a Poisson process. Explicit formulas for the distribution function of the first exit time for the Poisson process were obtained by Delucia and Poor [6] and Rolski et al. [7]. The Laplace Stieltjes transforms of the distribution function of the first exit time with positive jumps were given by Bar-Lev et al. [8] for the compound Poisson process where $Y_{i}, i=1,2, \ldots$, were continuous random variables. The explicit distribution function of the first exit time for the compound Poisson process was obtained by Ozel and Inal [9] where $Y_{i}, i=1,2, \ldots$, are discrete random variables.

In this study it is assumed that $\left\{\mathrm{N}_{\mathrm{t}}, \mathrm{t} \geq 0\right\}$ is a Poisson process with parameter $\lambda>0$ and $Y_{i}, i=1,2, \ldots$, are discrete random variables representing the positive integer-valued jump sizes. The mean first exit time is obtained for the compound Poisson process with an upper horizontal boundary and positive integer-valued jump sizes. The paper is organized as follows. We start by introducing in Section 2 the probability function of $\mathrm{X}_{\mathrm{t}}$ and the distribution function of the first exit time for the compound Poisson process. In Section 3, we derive the mean first exit time for compound Poisson process with an upper horizontal boundary and positive integer-valued jump sizes. Finally, an application to the traffic accidents is presented in Section 4 . The conclusion is given in Section 5.

\section{Some Preliminary Results On The Compound Poisson Process}

Let $Y_{i}, i=1,2, \ldots$, be discrete random variables and let $\left\{N_{t}, t \geq 0\right\}$ be a homogeneous Poisson process. The probability function of $\mathrm{X}_{\mathrm{t}}$ is given by

$$
\mathrm{p}_{\mathrm{X}_{\mathrm{t}}}(\mathrm{k})=\mathrm{P}\left(\mathrm{X}_{\mathrm{t}}=\mathrm{k}\right)=\sum_{\mathrm{n}=0}^{\infty} \mathrm{e}^{-\lambda \mathrm{t}} \frac{(\lambda \mathrm{t})^{\mathrm{n}}}{\mathrm{n} !} \mathrm{p}_{\mathrm{Y}}^{(\mathrm{n})}(\mathrm{k}), \quad \mathrm{k}=0,1,2, \ldots
$$

where $\mathrm{p}_{\mathrm{Y}}{ }^{(0)}(\mathrm{k})=\mathrm{P}(\mathrm{k}=0)$ and $\mathrm{p}_{\mathrm{Y}}{ }^{(\mathrm{n})}(\mathrm{k})$ is the $\mathrm{n}$-fold convolution of $\mathrm{P}\left(\mathrm{Y}_{\mathrm{i}}=\mathrm{j}\right)=\mathrm{p}_{\mathrm{j}}$, $\mathrm{j}=1,2, \ldots$ However, it is not easy to yield the explicit probabilities of $\mathrm{X}_{\mathrm{t}}$ from (2) since it needs infinite sum [7]. Therefore, a recursive algorithm was derived by Panjer [10] for $X_{t}$ satisfying the relation 


$$
\mathrm{p}_{\mathrm{N}_{\mathrm{t}}}(\mathrm{n})=\frac{\lambda \mathrm{t}}{\mathrm{n}} \mathrm{p}_{\mathrm{N}_{\mathrm{t}}}(\mathrm{n}-1), \mathrm{n}=1,2, \ldots
$$

Then the following recursion holds for $\mathrm{p}_{\mathrm{X}_{\mathrm{t}}}(\mathrm{k})$

$$
\begin{gathered}
\mathrm{p}_{\mathrm{X}_{\mathrm{t}}}(0)=\mathrm{e}^{-\lambda \mathrm{t}\left(1-\mathrm{p}_{\mathrm{Y}}(0)\right)}, \\
\mathrm{p}_{\mathrm{X}_{\mathrm{t}}}(\mathrm{k})=\lambda \mathrm{t} \sum_{\mathrm{i}=1}^{\mathrm{k}} \frac{\mathrm{i}}{\mathrm{k}} \mathrm{p}_{\mathrm{Y}}(\mathrm{i}) \mathrm{p}_{\mathrm{X}_{\mathrm{t}}}(\mathrm{y}-\mathrm{i}),
\end{gathered}
$$

where $p_{Y}(y)$ is the common probability function of $Y_{i}, i=1,2, \ldots$ The recursion in (3) starts with the calculated value of $P\left(X_{t}=0\right)=e^{-\lambda t\left(1-p_{Y}(0)\right)}$. As an example, in risk analysis for large insurance portfolios, this probability is very small, sometimes smaller than the smallest number that can be represented on the computer. When this occurs, this initial value is represented on the computer as zero and the recursion in (3) fails.

The explicit probability function of $X_{t}$ was derived by Ozel and Inal [2] as follows where $\left\{\mathrm{N}_{\mathrm{t}}, \mathrm{t} \geq 0\right\}$ be a homogeneous Poisson process with parameter $\lambda>0$ and $\lambda_{\mathrm{j}}=\lambda \mathrm{p}_{\mathrm{j}}$, $\mathrm{j}=1,2, \ldots$. If $\mathrm{Y}_{\mathrm{i}}, \mathrm{i}=1,2, \ldots$, are discrete random variables with the probabilities $P\left(Y_{i}=j\right)=p_{j}, j=0,1,2$, the explicit formula for the probability function of $X_{t}$ is given by

$$
\begin{aligned}
& \mathrm{P}\left(\mathrm{X}_{\mathrm{t}}=0\right)=\mathrm{e}^{-\lambda \mathrm{t}\left(1-\mathrm{p}_{0}\right)}, \\
& \mathrm{P}\left(\mathrm{X}_{\mathrm{t}}=1\right)= \mathrm{e}^{-\lambda \mathrm{t}\left(1-\mathrm{p}_{0}\right)} \frac{\left(\lambda_{1} \mathrm{t}\right)}{1 !}, \\
& \mathrm{P}\left(\mathrm{X}_{\mathrm{t}}=2\right)=\mathrm{e}^{-\lambda \mathrm{t}\left(1-\mathrm{p}_{0}\right)}\left[\frac{\left(\lambda_{1} \mathrm{t}\right)^{2}}{2 !}+\frac{\left(\lambda_{2} \mathrm{t}\right)}{1 !}\right], \\
& \mathrm{P}\left(\mathrm{X}_{\mathrm{t}}=3\right)=\mathrm{e}^{-\lambda \mathrm{t}\left(1-\mathrm{p}_{0}\right)}\left[\frac{\left(\lambda_{1} \mathrm{t}\right)^{3}}{3 !}+\frac{\left(\lambda_{1} \mathrm{t}\right)\left(\lambda_{2} \mathrm{t}\right)}{1 ! 1 !}+\frac{\left(\lambda_{3} \mathrm{t}\right)}{1 !}\right], \\
& \mathrm{P}\left(\mathrm{X}_{\mathrm{t}}=4\right)=\mathrm{e}^{-\lambda \mathrm{t}\left(1-\mathrm{p}_{0}\right)}\left[\frac{\left(\lambda_{1} \mathrm{t}\right)^{4}}{4 !}+\frac{\left(\lambda_{1} \mathrm{t}\right)^{2}\left(\lambda_{2} \mathrm{t}\right)}{2 ! 1 !}+\frac{\left(\lambda_{1} \mathrm{t}\right)\left(\lambda_{3} \mathrm{t}\right)}{1 ! 1 !}+\frac{\left(\lambda_{2} \mathrm{t}\right)^{2}}{2 !}+\frac{\left(\lambda_{4} \mathrm{t}\right)}{1 !}\right], \\
& \mathrm{P}\left(\mathrm{X}_{\mathrm{t}}=5\right)=\mathrm{e}^{-\lambda \mathrm{t}\left(1-\mathrm{p}_{0}\right)}\left[\frac{\left(\lambda_{1} \mathrm{t}\right)^{5}}{5 !}+\frac{\left(\lambda_{1} \mathrm{t}\right)^{3}\left(\lambda_{2} \mathrm{t}\right)}{3 ! 1 !}+\frac{\left(\lambda_{1} \mathrm{t}\right)^{2}\left(\lambda_{3} \mathrm{t}\right)}{2 ! 1 !}+\frac{\left(\lambda_{1} \mathrm{t}\right)\left(\lambda_{2} \mathrm{t}\right)^{2}}{2 ! 1 !}+\frac{\left(\lambda_{1} \mathrm{t}\right)\left(\lambda_{4} \mathrm{t}\right)}{1 ! 1 !}\right. \\
&\left.+\frac{\left(\lambda_{2} \mathrm{t}\right)\left(\lambda_{3} \mathrm{t}\right)}{1 ! 1 !}+\frac{\left(\lambda_{5} \mathrm{t}\right)}{1 !}\right],
\end{aligned}
$$


The probabilities in (5) can be used if $Y_{i}, i=1,2,3, \ldots$, have infinite values $j=1,2,3, \ldots$ and the probability $P\left(Y_{i}=j\right), \lambda_{j}=\lambda p_{j}$ approaches zero for $j \rightarrow \infty$. The probabilities $\mathrm{P}\left(\mathrm{X}_{\mathrm{t}}=\mathrm{k}\right), \mathrm{k}=0,1,2, \ldots$, are obtained from (5) and presented in Figures 1-3. Note that $\left\{\mathrm{X}_{\mathrm{t}}, \mathrm{t} \geq 0\right\}$ is also called as a Neyman type A process in Figure 1 and $\left\{\mathrm{N}_{\mathrm{t}}, \mathrm{t} \geq 0\right\}$ is a Poisson process with different values of $\lambda$ and $t=5$.

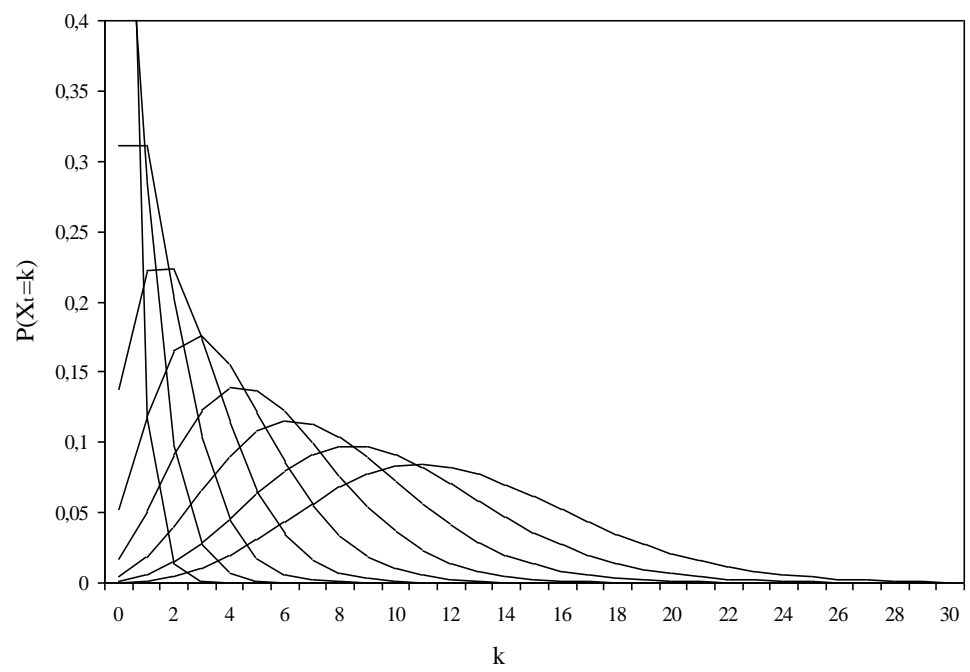

Figure 1: $\mathrm{P}\left(\mathrm{X}_{\mathrm{t}}=\mathrm{k}\right), \mathrm{k}=0,1,2, \ldots$, with $\mathrm{E}\left(\mathrm{X}_{\mathrm{t}}\right)=\lambda \mathrm{t} \mu=15$ where $\mathrm{Y}_{\mathrm{i}}, \mathrm{i}=1,2,3, \ldots$, are Poisson distributed. From the top the bottom $\mu$ taking values $1.0,0.9,0.8, \ldots, 0.1$, respectively.

$\mathrm{P}\left(\mathrm{X}_{\mathrm{t}}=\mathrm{k}\right), \mathrm{k}=0,1,2, \ldots$, are shown in Figure 2 where $\mathrm{Y}_{\mathrm{i}}, \mathrm{i}=1,2,3, \ldots$, are binomial distributed with parameters $(m, p)$ chosen such as $E(X)=\lambda$ tmp $=15$ and $m=20$. Note that $\left\{\mathrm{X}_{\mathrm{t}}, \mathrm{t} \geq 0\right\}$ is also called as a Neyman type B process. 


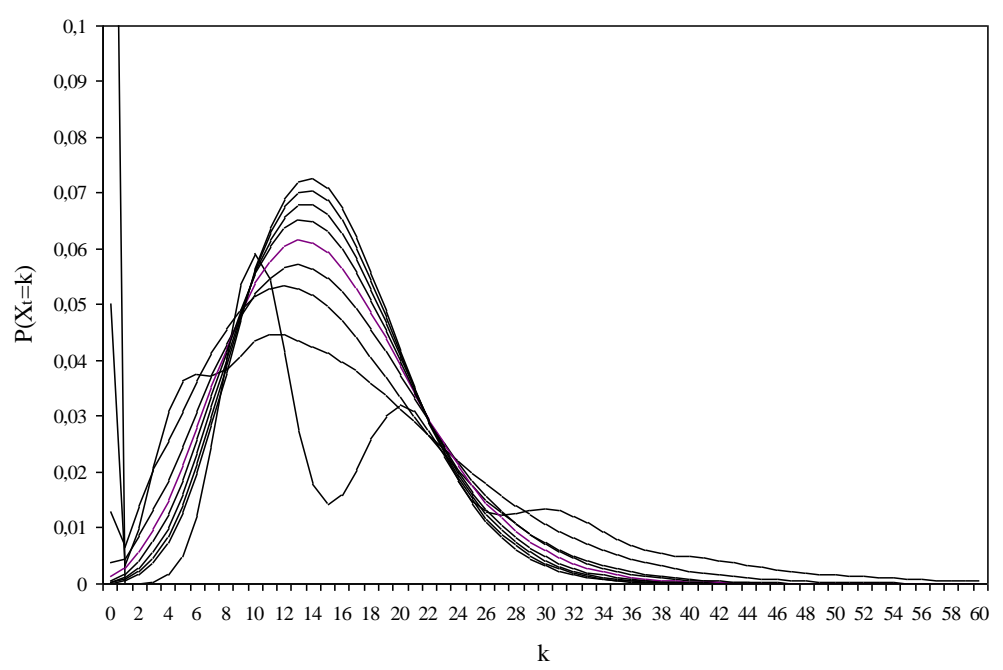

Figure 2: $\mathrm{P}\left(\mathrm{X}_{\mathrm{t}}=\mathrm{k}\right), \mathrm{k}=0,1,2, \ldots$, with $\mathrm{E}\left(\mathrm{X}_{\mathrm{t}}\right)=\lambda \mathrm{tmp}=15$ and $m=20$ where $\mathrm{Y}_{\mathrm{i}}, \mathrm{i}=1,2,3, \ldots$, are binomial distributed. From the top the bottom $\mathrm{p}$ taking values $0.05,0.06,0.07,0.08,, 0.5$, respectively.

Finally, $\mathrm{P}\left(\mathrm{X}_{\mathrm{t}}=\mathrm{k}\right), \mathrm{k}=0,1,2, \ldots$, are presented in Figure 3 where $\mathrm{Y}_{\mathrm{i}}, \mathrm{i}=1,2,3, \ldots$, are geometric distributed with parameter $\theta$ chosen such as $E\left(X_{t}\right)=\lambda / \theta=15$. Note that $\left\{\mathrm{X}_{\mathrm{t}}, \mathrm{t} \geq 0\right\}$ is also called as a Polya-Aeppli process.

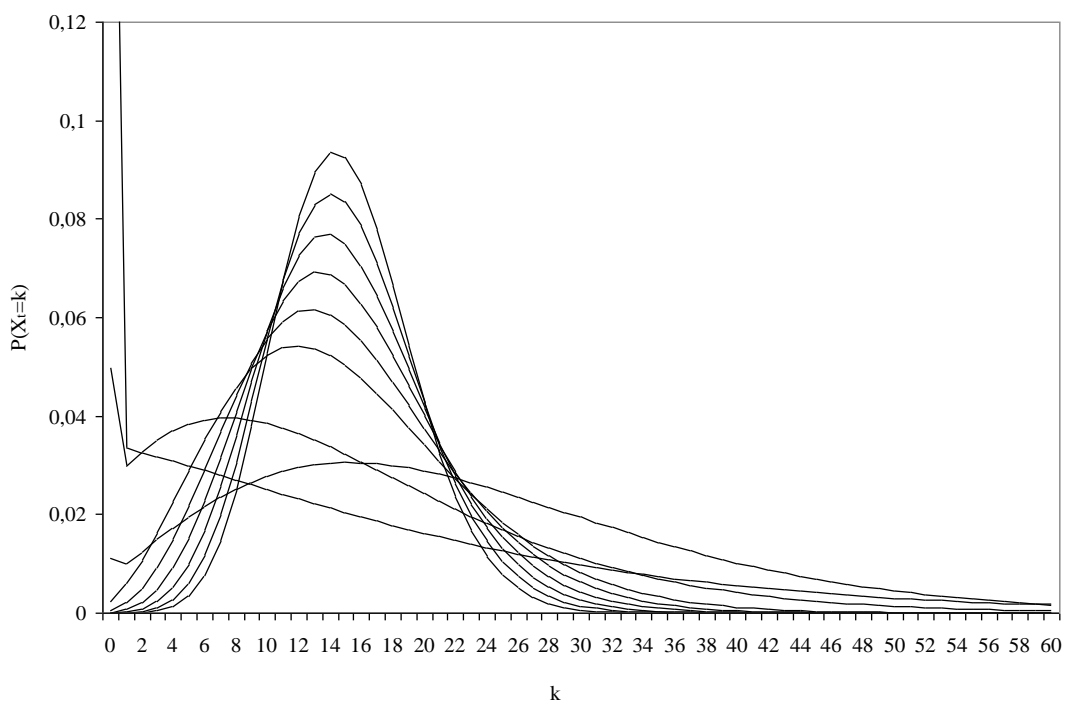

Figure 3: $\mathrm{P}\left(\mathrm{X}_{\mathrm{t}}=\mathrm{k}\right), \mathrm{k}=0,1,2, \ldots$, with $\mathrm{E}\left(\mathrm{X}_{\mathrm{t}}\right)=\lambda \mathrm{t} / \theta=15 \mathrm{Y}_{\mathrm{i}}, \mathrm{i}=1,2,3, \ldots$, are geometric distributed.

From the top the bottom $\theta$ taking values $1.0,0.9,0.8, \ldots, 0.1$, respectively. 
Now consider an upper horizontal boundary $\beta$ and the first exit time $\mathrm{T}$ is defined as

$$
\mathrm{T}=\inf \left\{\mathrm{t}: \mathrm{X}_{\mathrm{t}} \geq \beta\right\}
$$

where $0<\mathrm{t}<\infty$ and $\beta>0$. T can be described as the first instant at which a sample path crosses (jumps over) the boundary $\beta$.

Applications related with the distribution function of the first exit time are varied in probability and statistics, including financial mathematics, reliability, queues, inventory theory and sequential analysis; see, for instance, Gallot [11], Ignatov and Kaishev [12]. In all of these studies $\mathrm{Y}_{\mathrm{i}}, \mathrm{i}=1,2,3, \ldots$, were defined as continuous random variables. The distribution function of the first exit time was considered by Ozel and Inal [9] for the compound Poisson process with an upper boundary where $\mathrm{Y}_{\mathrm{i}}, \mathrm{i}=1,2, \ldots$, are discrete random variables. Since $\left\{X_{t}, t \geq 0\right\}$ is an increasing process, we have $P(T>t)=F_{X_{t}}(\beta-1)$. Then the distribution function of $\mathrm{T}$ is given by

$$
\begin{aligned}
\mathrm{F}_{\mathrm{T}}(\mathrm{t}) & =\mathrm{P}(\mathrm{T} \leq \mathrm{t})=1-\mathrm{P}\left(\mathrm{X}_{\mathrm{t}} \leq \beta-1\right) \\
& =1-\mathrm{F}_{\mathrm{X}_{\mathrm{t}}}(\beta-1) .
\end{aligned}
$$

The distribution function of $\mathrm{T}$ is obtained as given below if the cumulative probabilities in (7) substituted into (6)

$$
\begin{aligned}
\mathrm{F}_{\mathrm{X}_{\mathrm{t}}}(0) & =\mathrm{e}^{-\lambda \mathrm{t}\left(1-\mathrm{p}_{0}\right)} \\
\mathrm{F}_{\mathrm{X}_{\mathrm{t}}}(1) & =\mathrm{F}_{\mathrm{X}_{\mathrm{t}}}(0)+\mathrm{F}_{\mathrm{X}_{\mathrm{t}}}(0) \frac{\left(\lambda_{1} \mathrm{t}\right)}{1 !}, \\
\mathrm{F}_{\mathrm{X}_{\mathrm{t}}}(3) & =\mathrm{F}_{\mathrm{X}_{\mathrm{t}}}(2)+\left[\frac{\left(\lambda_{1} \mathrm{t}\right)^{3}}{3 !}+\frac{\left(\lambda_{1} \mathrm{t}\right)\left(\lambda_{2} \mathrm{t}\right)}{1 ! 1 !}+\frac{\left.\left(\lambda_{3} \mathrm{t}\right)\right]}{1 !}\right] \\
\mathrm{F}_{\mathrm{X}_{\mathrm{t}}}(4) & =\mathrm{F}_{\mathrm{X}_{\mathrm{t}}}(3)+\left[\frac{\left(\lambda_{1} \mathrm{t}\right)^{4}}{4 !}+\frac{\left(\lambda_{1} \mathrm{t}\right)^{2}\left(\lambda_{2} \mathrm{t}\right)}{2 ! 1 !}+\frac{\left(\lambda_{1} \mathrm{t}\right)\left(\lambda_{3} \mathrm{t}\right)}{1 ! 1 !}+\frac{\left(\lambda_{2} \mathrm{t}\right)^{2}}{2 !}+\frac{\left(\lambda_{4} \mathrm{t}\right)}{1 !}\right] \\
\mathrm{F}_{\mathrm{X}_{\mathrm{t}}}(5) & =\mathrm{F}_{\mathrm{X}_{\mathrm{t}}}(4)+\left[\frac{\left(\lambda_{1} \mathrm{t}\right)^{5}}{5 !}+\frac{\left(\lambda_{1} \mathrm{t}\right)^{3}\left(\lambda_{2} \mathrm{t}\right)}{3 ! 1 !}+\frac{\left(\lambda_{1} \mathrm{t}\right)^{2}\left(\lambda_{3} \mathrm{t}\right)}{2 ! 1 !}+\frac{\left(\lambda_{1} \mathrm{t}\right)\left(\lambda_{2} \mathrm{t}\right)^{2}}{1 ! 2 !}+\frac{\left(\lambda_{1} \mathrm{t}\right)\left(\lambda_{4} \mathrm{t}\right)}{1 ! 1 !}\right. \\
& \left.+\frac{\left(\lambda_{2} \mathrm{t}\right)\left(\lambda_{3} \mathrm{t}\right)}{1 !}+\frac{\left(\lambda_{5} \mathrm{t}\right)}{1 !}\right]
\end{aligned}
$$


Some numerical examples of $\mathrm{F}_{\mathrm{T}}(\mathrm{t})$ are presented in Figures 4-6 using the algorithm of $\mathrm{F}_{\mathrm{T}}(\mathrm{t})$. In these figures the upper horizontal boundary is taken as $\beta=10$ and $\left\{\mathrm{N}_{\mathrm{t}}, \mathrm{t} \geq 0\right\}$ is a Poisson process with parameter $\lambda$ taking several values. The distribution function of $\mathrm{T}$ is given in Figure 4 where $Y_{i}, i=1,2, \ldots$, have Poisson distribution with $\mu=1.5$ and $F_{T}(t)$ is shown where $Y_{i}, i=1,2, \ldots$, have binomial distribution with parameters $(p=0.2, m=5)$ in Figure 5 . Finally, the distribution functions of $T$ are presented in Figure 6 where $Y_{i}, i=1,2, \ldots$, have geometric distribution with parameter $\theta=0.6$.

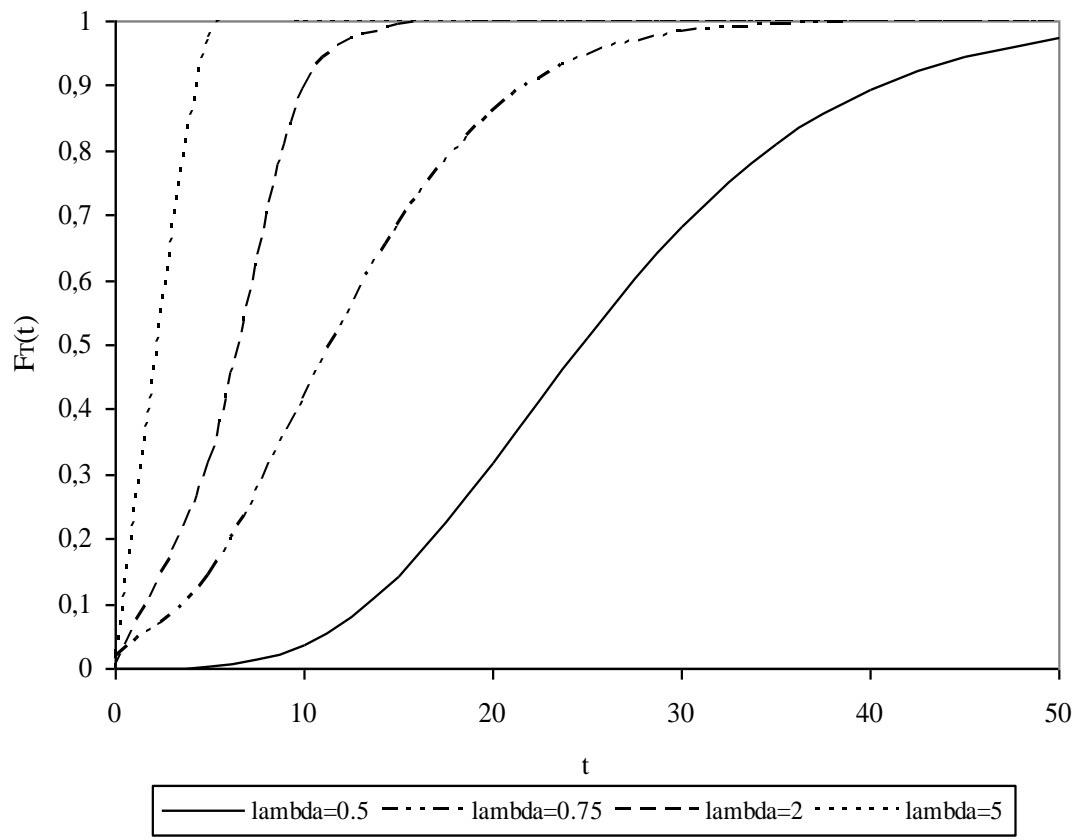

Figure 4:The distribution function of $T$ with $\beta=10$ for several values of $t$ where $Y_{i}, i=1,2, \ldots$, have Poisson distribution with parameter $\mu=1.5$. 


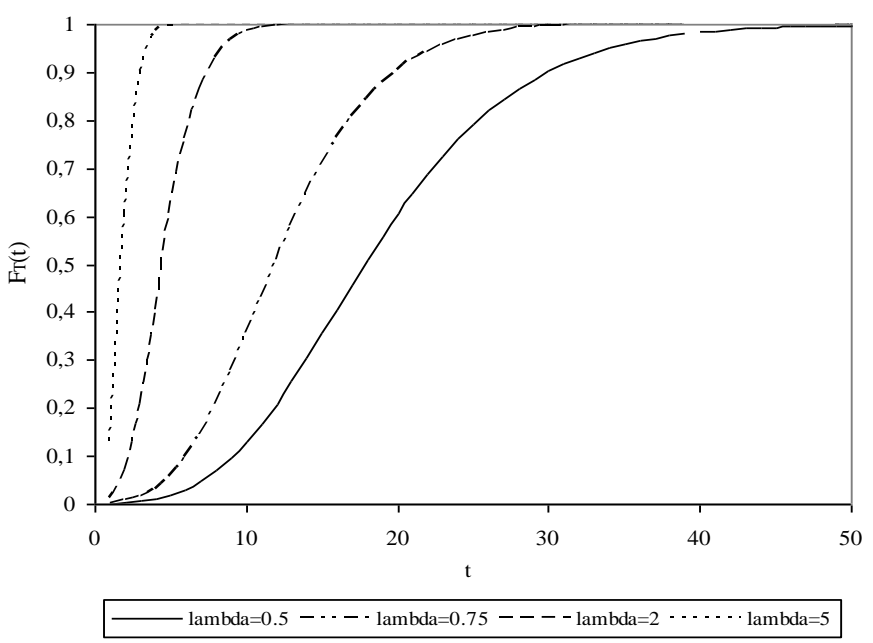

Figure 5: The distribution functions of $T$ with $\beta=10$ for several values of $t$ where $Y_{i}, i=1,2, \ldots$, have binomial distribution with parameters $(\mathrm{p}=0.2, \mathrm{~m}=5)$.

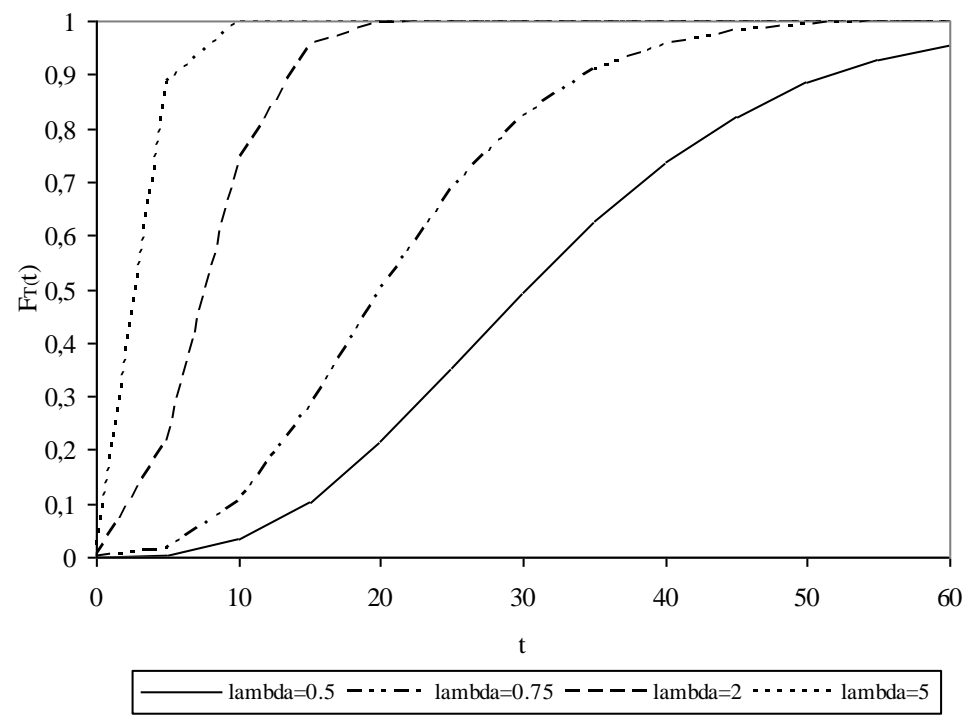

Figure 6: The distribution functions of $T$ with $\beta=10$ for several values of $t$ where $Y_{i}, i=1,2, \ldots$, have geometric distribution with parameter $\theta=0.6$. 


\section{Mean First Exit Time}

In this section, mean the first exit time $\mathrm{E}(\mathrm{T})$ is obtained for the compound Poisson process where $Y_{i}, i=1,2,3, \ldots$, are discrete random variables.

Let $\mathrm{E}(\mathrm{T})$ be the mean first time at which a given compound Poisson process hits a given subset of the state space. Let $\beta$ be the upper horizontal boundary for (6), we obtain from (6)

$$
\mathrm{P}(\mathrm{T}>\mathrm{t})=\sum_{\mathrm{k}=0}^{\beta-1} \mathrm{P}\left(\mathrm{X}_{\mathrm{t}}=\mathrm{k}\right)
$$

and taking the expectation we obtain

$$
E(T)=\int_{0}^{\infty} P(T>t) d t
$$

where $0<\mathrm{t}<\infty . \mathrm{P}(\mathrm{T}>\mathrm{t})$ is obtained for $\beta=1$ from (8) as

$$
\mathrm{P}(\mathrm{T}>\mathrm{t})=\mathrm{e}^{-\lambda \mathrm{t}\left[1-\mathrm{P}\left(\mathrm{X}_{\mathrm{t}}=0\right)\right]}
$$

Taking expectation of (10), the mean first exit time for $\beta=1$ is obtained by

$$
E(T)=\frac{1}{\lambda t\left(1-p_{0}\right)}
$$

where $P\left(Y_{i}=j\right)=p_{j}, j=0,1,2, \ldots$ Similarly we obtain the mean first exit time for $\beta>1$ as

$$
\begin{aligned}
& E(T)=\frac{1}{\lambda t\left(1-p_{0}\right)}+\frac{\lambda_{1} t}{\left[\lambda t\left(1-p_{0}\right)\right]^{2}}, \text { for } \beta=2 \\
& E(T)=\frac{1}{\lambda t\left(1-p_{0}\right)}+\frac{\left(\lambda_{1} t+\lambda_{2} t\right)}{\left[\lambda t\left(1-p_{0}\right)\right]^{2}}+\frac{\left(\lambda_{1} t\right)^{2}}{\left[\lambda t\left(1-p_{0}\right)\right]^{3}}, \quad \text { for } \beta=3 \\
& E(T)=\frac{1}{\lambda t\left(1-p_{0}\right)}+\frac{\left(\lambda_{1} t+\lambda_{2} t+\lambda_{3} t\right)}{\left[\lambda t\left(1-p_{0}\right)\right]^{2}}+\frac{\left(\lambda_{1} t\right)^{2}+2\left(\lambda_{1} t\right)\left(\lambda_{2} t\right)}{\left[\lambda t\left(1-p_{0}\right)\right]^{3}}+\frac{\left(\lambda_{1} t\right)^{3}}{\left[\lambda t\left(1-p_{0}\right)\right]^{4}}, \text { for } \beta=4
\end{aligned}
$$




$$
\begin{aligned}
& E(T)=\frac{1}{\lambda t\left(1-p_{0}\right)}+\frac{\left(\lambda_{1} t+\lambda_{2} t+\lambda_{3} t+\lambda_{4} t\right)}{\left[\lambda t\left(1-p_{0}\right)\right]^{2}}+\frac{\left(\lambda_{1} t\right)^{2}+2\left(\lambda_{1} t\right)\left(\lambda_{2} t\right)+2\left(\lambda_{1} t\right)\left(\lambda_{3} t\right)+\left(\lambda_{2} t\right)^{2}}{\left[\lambda t\left(1-p_{0}\right)\right]^{3}} \\
& +\frac{\left(\lambda_{1} t\right)^{3}+3\left(\lambda_{1} t\right)^{2}\left(\lambda_{2} t\right)}{\left[\lambda t\left(1-p_{0}\right)\right]^{4}}+\frac{\left(\lambda_{1} t\right)^{4}}{\left[\lambda t\left(1-p_{0}\right)\right]^{5}}, \text { for } \beta=5
\end{aligned}
$$

where $\lambda_{j}=\lambda p_{j}, j=1,2, \ldots$

According to the mean first exit time $\mathrm{E}(\mathrm{T})$, the right-hand side terms depend on how $\beta$ can be partitioned into different forms with using integers $1,2, \ldots$ To obtain $E(T)$, a new algorithm is prepared in R. A summary outline of the basic steps and operations for the algorithm is given as

Step 1 Determine the value of parameter $\lambda$ and initial parameters of the algorithm (t, $\beta$, and $\left.P\left(Y_{i}=j\right)=p_{j}, j=0,1,2, \ldots\right)$.

Step 2 Multiply each terms of $E(T)$ for $\beta$ with $\frac{\left(\lambda_{1} t\right)}{\left[\lambda t\left(1-p_{0}\right)\right]}$ for each expected value $E(T)$ for $\beta-1$ and keep the numerical values of this step.

Step 3 Form the new $\lambda_{j}, j=2,3, \ldots$ terms beginning from $E(T)$ for $\beta-2$ to $E(T)$ for $\beta-[\beta / 2]$ and keep the numerical values of this step.

Step 4 Multiply $\lambda_{j}, j=2,3, \ldots$ terms of Step 3 with $\frac{\left(\lambda_{1} t\right)}{\left[\lambda t\left(1-p_{0}\right)\right]}$ and keep the numerical values of this step.

Step 5 Add the numerical values of Steps 1,2 and 3 and add $\frac{1}{\left[\lambda t\left(1-p_{0}\right)\right]}$. Then obtain the final $\mathrm{E}(\mathrm{T})$ for $2,3, \ldots$

\section{Numerical Example}

Meintanis [13] obtained a new goodness of fit test for certain bivariate distributions based on accident data and fatalities in The Netherlands. The data were obtained from the database of BRON of the Ministry of Transport, The Netherlands. In particular, total accidents and fatalities recorded on Sundays of each month over the period 1997-2004 in the region of Groningen are given in Table 1. 
Table 1: Total Sunday accidents (left entry) and the corresponding number of fatalities (right entry) recorded in the region Groningen for each month during the years 1997-2004.

\begin{tabular}{l|rl|rl|rl|rl|rr|rr|rr|rr}
\hline Month & \multicolumn{1}{|c|}{1997} & \multicolumn{1}{|c|}{1998} & \multicolumn{1}{|c|}{1999} & \multicolumn{2}{|c|}{2000} & \multicolumn{2}{|c|}{2001} & \multicolumn{2}{|c|}{2002} & \multicolumn{2}{|c|}{2003} & \multicolumn{2}{c}{2004} \\
\hline January & 6 & 0 & 6 & 0 & 13 & 1 & 11 & 0 & 8 & 0 & 8 & 0 & 11 & 4 & 2 & 0 \\
February & 10 & 0 & 10 & 1 & 7 & 0 & 4 & 0 & 8 & 1 & 8 & 0 & 9 & 0 & 2 & 0 \\
March & 7 & 0 & 13 & 4 & 8 & 0 & 10 & 0 & 6 & 0 & 12 & 0 & 9 & 0 & 3 & 0 \\
April & 11 & 0 & 5 & 0 & 14 & 1 & 15 & 1 & 9 & 0 & 10 & 1 & 7 & 1 & 1 & 1 \\
May & 12 & 0 & 17 & 2 & 13 & 0 & 18 & 0 & 13 & 2 & 11 & 0 & 12 & 1 & 5 & 0 \\
June & 21 & 1 & 19 & 0 & 14 & 0 & 21 & 1 & 12 & 3 & 12 & 1 & 13 & 0 & 7 & 2 \\
July & 15 & 0 & 10 & 0 & 14 & 0 & 11 & 1 & 10 & 2 & 4 & 0 & 8 & 0 & 1 & 0 \\
August & 11 & 1 & 11 & 1 & 10 & 0 & 8 & 0 & 9 & 0 & 14 & 1 & 6 & 0 & 5 & 0 \\
September & 7 & 0 & 11 & 0 & 7 & 0 & 9 & 0 & 22 & 1 & 16 & 1 & 7 & 0 & 8 & 1 \\
October & 11 & 2 & 13 & 1 & 16 & 1 & 14 & 0 & 15 & 1 & 8 & 1 & 6 & 1 & 2 & 0 \\
November & 15 & 1 & 17 & 1 & 13 & 0 & 13 & 0 & 6 & 0 & 9 & 1 & 11 & 1 & 1 & 0 \\
December & 5 & 0 & 7 & 0 & 10 & 1 & 10 & 0 & 10 & 0 & 8 & 0 & 5 & 0 & 2 & 0 \\
\hline
\end{tabular}

In this study the same data is used to show applicability of the compound Poisson process and the mean first exit time. For the construction of a model to explain the total number of fatalities from the accidents the following random variables are defined:

$N_{t}$ : The number of accidents which occur in Groningen between years 1997-2004;

$Y_{i}$ : The number of fatalities of $i^{\text {th }}$ accident such that $i=1,2,3, \ldots$;

$\mathrm{X}_{\mathrm{t}}$ : The total number of fatalities in the time interval $(0, \mathrm{t}]$.

We get $\mathrm{X}_{\mathrm{t}}=\sum_{\mathrm{i}=1}^{\mathrm{N}_{\mathrm{t}}} \mathrm{Y}_{\mathrm{i}}$ and we say that $\left\{\mathrm{X}_{\mathrm{t}}, \mathrm{t} \geq 0\right\}$ is a compound Poisson process if the following conditions are hold:

Condition 1. Fit of the Homogeneous Poisson Process to Accidents: Using goodness of fit test $\left(\chi^{2}=2.94\right.$, p-value $=0.57$, we have seen that the number of the accidents which occur in Groningen between years 1997-2004, defined as $\left\{\mathrm{N}_{\mathrm{t}}, \mathrm{t} \geq 0\right\}$, fit a homogeneous Poisson process with $\lambda=9.84$ (month). The probabilities of the traffic accidents for $t=1,2,3$ months are shown in Figure 7. 


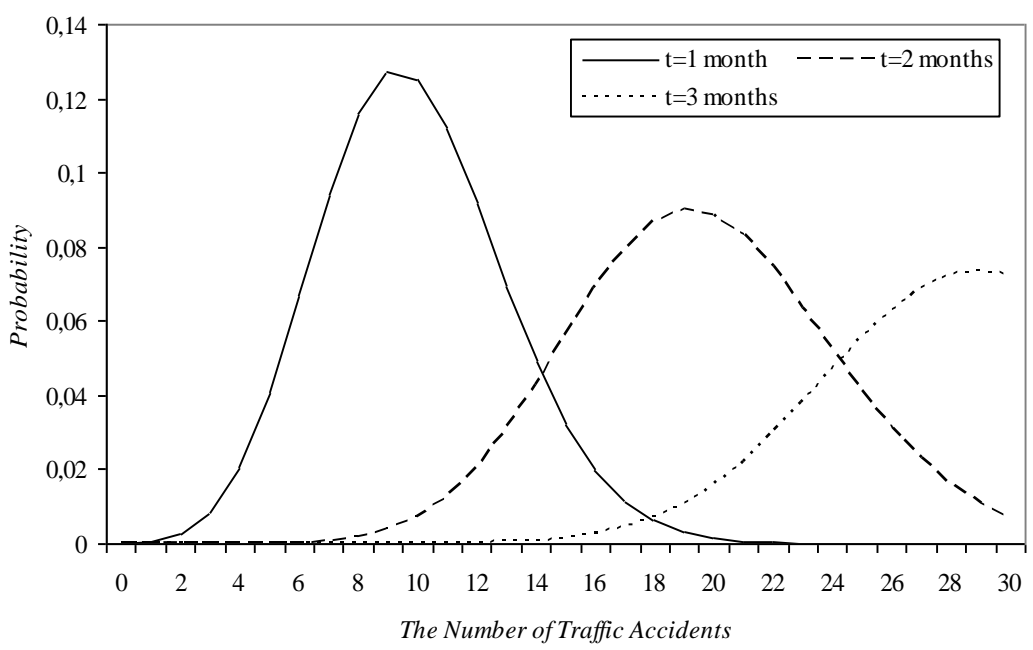

Figure 7: The occurrence probabilities of traffic accidents within $\mathrm{t}=1,2,3$ months.

Condition 2. Independence Test of the Process $\left\{N_{t}, t \geq 0\right\}$ and $Y_{i}, i=1,2,3, \ldots$ : Now it must be shown the independence of $\mathrm{Y}_{\mathrm{i}}, \mathrm{i}=1,2, \ldots$ and $\left\{\mathrm{N}_{\mathrm{t}}, \mathrm{t} \geq 0\right\}$. According to Spearman's $\rho$ test (Spearman's $\rho=0.084 ; p-$ value $=0.432$ ), the independence is accepted.

Condition 3. Fit of the Poisson, Binomial or Geometric Distributions to Fatalities: To decide the best distribution between Poisson distribution, binomial distribution and geometric distribution for the number of fatalities, the goodness of fit tests were performed and the results are presented in Table 2. It is seen in Table 2 that the chi-square values are less than the critical table values for each distribution at the $5 \%$ level of significance. This means that the Poisson distribution with parameter $\mu=0.53$, binomial distribution with parameters

$(\mathrm{m}=4, \mathrm{p}=0.13 ; \mathrm{p}$-value $=0.897)$ and geometric distribution with parameter $\theta=0.62$ significantly fit the data.

Table 2: Comparison of fit of Poisson and binomial distributions to observed frequency for fatalities

\begin{tabular}{ccccc}
\hline $\begin{array}{c}\text { Number of } \\
\text { Fatalities }\end{array}$ & $\begin{array}{c}\text { Observed } \\
\text { Frequency }\end{array}$ & Poisson & Expected Frequency \\
\hline 0 & 59 & 56.51 & 55.00 & Binomial \\
1 & 29 & 29.95 & 32.87 & 56.04 \\
2 & 5 & 7.94 & 7.37 & 22.73 \\
3 & 1 & 1.40 & 0.73 & 8.75 \\
4 & 2 & 0.19 & 0.03 & 3.37 \\
\hline Total & 96 & 96.00 & 96.00 & 1.30 \\
\hline Chi-Square & & 0.202 & 1.519 & 95.18 \\
\hline d.f. & & 2 & 3 & 0.057 \\
\hline
\end{tabular}


For our data, binomial distribution is more appropriate than geometric and Poisson distributions for the random variables $Y_{i}, i=1,2,3, \ldots$, since the number of fatalities are small. Since all conditions are hold, it can be said that $\left\{\mathrm{X}_{\mathrm{t}}, \mathrm{t} \geq 0\right\}$ is a compound Poisson process. So, the probabilities $\mathrm{P}\left(\mathrm{X}_{\mathrm{t}}=\mathrm{k}\right), \mathrm{k}=0,1,2, \ldots$, and the mean first exit time can be computed easily. The probabilities of the total number of fatalities for $\mathrm{t}=1,2,3$ months are given in Figure 9.

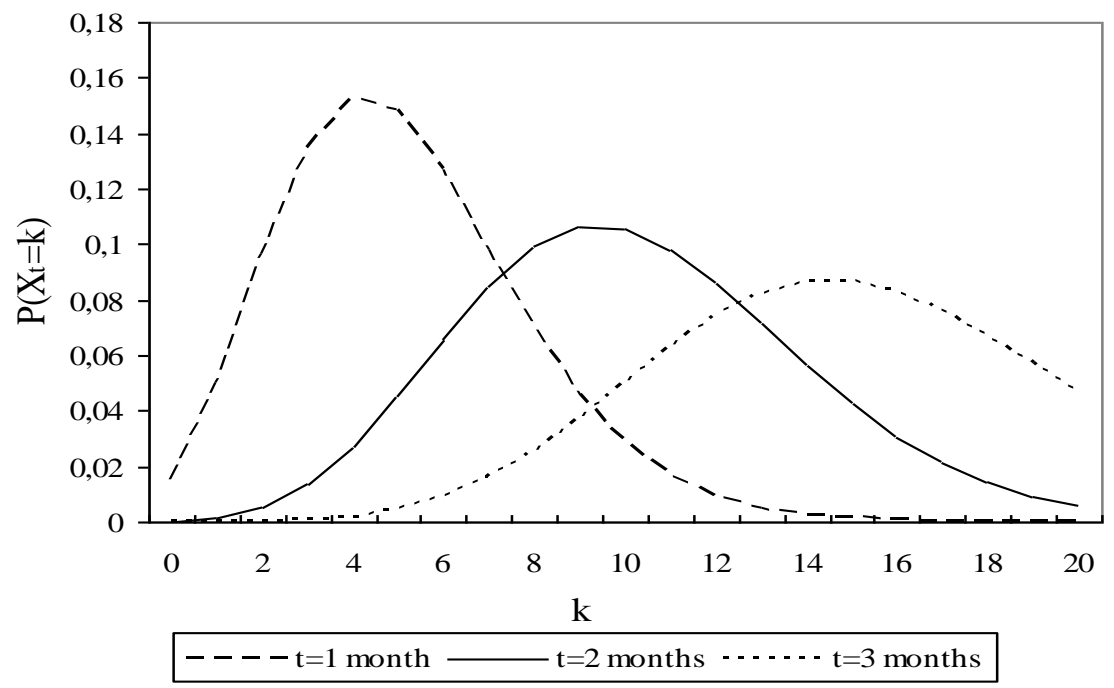

Figure 9: The probability of total fatality number which will occur within $t=1,2,3$ months

The distribution functions of $\mathrm{T}$ are presented in Figure 10 where the random variables $\mathrm{Y}_{\mathrm{i}}$, $\mathrm{i}=1,2, \ldots$, have binomial distribution with parameters $\mathrm{p}=0.13$ and $\mathrm{m}=4$. In Figure 10, $\left\{N_{t}, t \geq 0\right\}$ is a homogeneous Poisson process with $\lambda=9.84$ and the upper horizontal boundaries are taken as $\beta=5$ and $\beta=10$. 


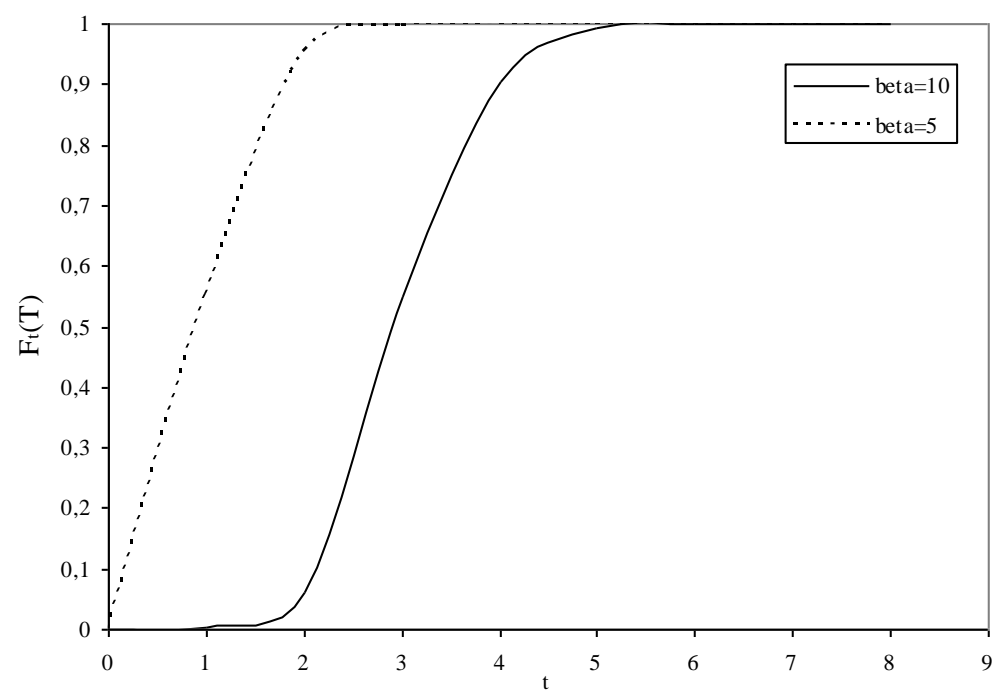

Figure 10: The distribution functions of $\mathrm{T}$ for $\beta=5$ and $\beta=10$ with several values of $\mathrm{t}$ where $\mathrm{Y}_{\mathrm{i}}$, $\mathrm{i}=1,2, \ldots$, have binomial distribution with parameters $(\mathrm{p}=0.13, \mathrm{~m}=4)$.

Mean exit time $\mathrm{E}(\mathrm{T})$ is obtained from (11) for $\beta=1,2,3,4,5$ with several values of $\mathrm{t}$ where $Y_{i}, i=1,2, \ldots$, have binomial distribution with parameters $(p=0.13, m=4)$ and presented in Table 3. 
Table 3: Mean exit time $\mathrm{E}(\mathrm{T})$ for $\beta=1,2,3,4,5$ with several values of $\mathrm{t}$ where $\mathrm{Y}_{\mathrm{i}}, i=1,2, \ldots$, have binomial distribution with parameters $(\mathrm{p}=0.13, \mathrm{~m}=4)$.

\begin{tabular}{|c|c|c|c|c|c|}
\hline \multirow[b]{2}{*}{$\mathrm{t}$ (month) } & \multicolumn{5}{|c|}{$\beta$} \\
\hline & 1 & 2 & 3 & 4 & 5 \\
\hline 1 & 0,0510 & 0,3530 & 0,3580 & 0,7 & 1,5 \\
\hline 2 & 0,1019 & 0,1765 & 0,2555 & 5,4 & 25,5 \\
\hline 3 & 0,1529 & 0,1177 & 0,2553 & 25,9 & 174,9 \\
\hline 4 & 0,2039 & 0,0883 & 0,2807 & 81,3 & 701,1 \\
\hline 5 & 0,2549 & 0,0706 & 0,3163 & 198,1 & 2074,8 \\
\hline 6 & 0,3058 & 0,0588 & 0,3570 & 410,5 & 5055,8 \\
\hline 7 & 0,3568 & 0,0504 & 0,4007 & 760,2 & 10762,7 \\
\hline 8 & 0,4078 & 0,0441 & 0,4462 & 1296,7 & 20742,8 \\
\hline 9 & 0,4588 & 0,0392 & 0,4929 & 2076,8 & 37041,7 \\
\hline 10 & 0,5097 & 0,0353 & 0,5404 & 3165,1 & 62273,5 \\
\hline 11 & 0,5607 & 0,0321 & 0,5886 & 4633,9 & 99690,0 \\
\hline 12 & 0,6117 & 0,0294 & 0,6373 & 6562,8 & 153251,0 \\
\hline 13 & 0,6627 & 0,0272 & 0,6863 & 9039,1 & 227693,9 \\
\hline 14 & 0,7136 & 0,0252 & 0,7356 & 12157,9 & 328603,5 \\
\hline 15 & 0,7646 & 0,0235 & 0,7851 & 16021,6 & 462481,7 \\
\hline 16 & 0,8156 & 0,0221 & 0,8348 & 20740,4 & 636817,5 \\
\hline 17 & 0,8665 & 0,0208 & 0,8846 & 26432,0 & 860156,7 \\
\hline 18 & 0,9175 & 0,0196 & 0,9346 & 33221,7 & 1142171,6 \\
\hline 19 & 0,9685 & 0,0186 & 0,9847 & 41242,4 & 1493731,0 \\
\hline 20 & 1,0195 & 0,0177 & 1,0348 & 50634,7 & 1926969,8 \\
\hline 21 & 1,0704 & 0,0168 & 1,0851 & 61546,6 & 2455358,9 \\
\hline 22 & 1,1214 & 0,0160 & 1,1354 & 74133,8 & 3093774,9 \\
\hline 23 & 1,1724 & 0,0153 & 1,1857 & 88559,7 & 3858570,1 \\
\hline 24 & 1,2234 & 0,0147 & 1,2362 & 104995,1 & 4767642,0 \\
\hline 25 & 1,2743 & 0,0141 & 1,2866 & 123618,5 & 5840503,3 \\
\hline 26 & 1,3253 & 0,0136 & 1,3371 & 144616,0 & 7098351,7 \\
\hline 27 & 1,3763 & 0,0131 & 1,3877 & 168181,3 & 8564139,7 \\
\hline 28 & 1,4273 & 0,0126 & 1,4382 & 194515,5 & 10262644,2 \\
\hline 29 & 1,4782 & 0,0122 & 1,4888 & 223827,7 & 12220536,4 \\
\hline 30 & 1,5292 & 0,0118 & 1,5394 & 256334,2 & 14466451,9 \\
\hline 31 & 1,5802 & 0,0114 & 1,5901 & 292259,1 & 17031059,9 \\
\hline 32 & 1,6312 & 0,0110 & 1,6407 & 331834,1 & 19947133,4 \\
\hline 33 & 1,6821 & 0,0107 & 1,6914 & 375298,4 & 23249619,2 \\
\hline 34 & 1,7331 & 0,0104 & 1,7421 & 422898,8 & 26975707,0 \\
\hline 35 & 1,7841 & 0,0101 & 1,7928 & 474889,7 & 31164899,8 \\
\hline 36 & 1,8350 & 0,0098 & 1,8436 & 531533,3 & 35859083,6 \\
\hline 37 & 1,8860 & 0,0095 & 1,8943 & 593099,1 & 41102596,8 \\
\hline 38 & 1,9370 & 0,0093 & 1,9451 & 659864,3 & 46942300,6 \\
\hline 39 & 1,9880 & 0,0091 & 1,9958 & 732113,8 & 53427648,3 \\
\hline 40 & 2,0389 & 0,0088 & 2,0466 & 810139,9 & 60610755,3 \\
\hline
\end{tabular}




\section{CONCLUSION}

We conclude with the comment that the mean first exit time $\mathrm{E}(\mathrm{T})$ can be computed easily if $\mathrm{p}_{0}=\mathrm{P}\left(\mathrm{Y}_{\mathrm{i}}=0\right), \mathrm{p}_{1}=\mathrm{P}\left(\mathrm{Y}_{\mathrm{i}}=1\right), \ldots, \mathrm{p}_{\mathrm{m}}=\mathrm{P}\left(\mathrm{Y}_{\mathrm{i}}=\mathrm{m}\right)$ are known for a compound Poisson process when the jump sizes are discrete random variables and the boundary is upper horizontal. Then, an application to traffic accident data is presented to illustrate the usage of the mean first exit time for the compound Poisson process.

\section{ACKNOWLEDGEMENT}

The author is grateful to the anonymous referee for his valuable suggestion that improved the presentation.

\section{REFERENCES}

[1]. G. Ozel and C. Inal, On the Probability Function of the First Exit Time for Generalized Poisson Processes, Pakistan Journal of Statistics 28, 27-40, 2012.

[2]. G. Ozel and C. Inal, The probability function of the compound Poisson process and an application to aftershock sequence in Turkey, Environmetrics 19, 79-85, 2008.

[3]. W.A. Rosencrantz, Calculation of the Laplace transform of the length of the busy period for the M/G/1 queue via martingales, Annals of Probability 11, 817-818, 1983.

[4]. Y.M.I. Dirickx and D. Koevoets, A continuous review inventory model with compound Poisson demand process and stochastic lead time, Naval Research Logistics Quarterly 24, 577-585, 1997.

[5]. A. Dvoretzky, J. Kiefer and J. Wolfowitz, Sequential decision problems for processes with continuous time parameter, Annals of Mathematical Statistics 24, 254-264, 1953.

[6]. J. Delucia and H.V. Poor, The moment generating function of the stopping time for a linearly stopped Poisson process, Stochastic Models 13, 275-292, 1997.

[7]. T. Rolski, H. Schmidli, V. Schmidt and J. Teugels, Stochastic Processes for Insurance and Finance, John Wiley \& Sons, 1998.

[8]. S. Bar-Lev, D. Bshouty, D. Perry and S. Zacks, Distributions of stopping times for compound Poisson processes, Stochastic Models 15, 89-101, 1999.

[9]. G. Ozel and C. Inal, Distribution Function of First Exit Time for a Compound Poisson Process, Anadolu University Journal of Science and Technology-B Theoretical Sciences 1, 91-104, 2011.

[10]. H.H. Panjer, Recursive evaluation of a family of compound distributions, Astin Bulletin 12, 22-26, 1981.

[11]. S.F.L. Gallot, Absorption and first passage times for a compound process in a general upper boundary, Journal of Applied Probability 30, 835-850, 1983.

[12]. Z.G. Ignatov and V.K. Kaishev, A finite-time ruin probability formula for continuous claim severities, Journal of Applied Probability 41, 570-578, 2004. 
[13]. S.G. Meintanis, A new goodness of fit test for certain bivariate distributions applicable to traffic accidents. Statistical Methodology 4, 22-34, 2007.

Gamze Ozel

Department of Statistics

Hacettepe University

06800, Ankara, Turkey. 
